\title{
Chagas disease: control, elimination and eradication. Is it possible?
}

\author{
José Rodrigues Coura/ ${ }^{+}$ \\ Laboratório de Doenças Parasitárias, Instituto Oswaldo Cruz-Fiocruz, Rio de Janeiro, RJ, Brasil
}

\begin{abstract}
From an epidemiological point of view, Chagas disease and its reservoirs and vectors can present the following characteristics: (i) enzooty, maintained by wild animals and vectors, with broad occurrence from southern United States of America (USA) to southern Argentina and Chile $\left(42^{\circ} \mathrm{N} 49^{\circ} \mathrm{S}\right.$ ), (ii) anthropozoonosis, when man invades the wild ecotope and becomes infected with Trypanosoma cruzi from wild animals or vectors or when the vectors and wild animals, especially marsupials, invade the human domicile and infect man, (iii) zoonosis-amphixenosis and exchanged infection between animals and humans by domestic vectors in endemic areas and (iv) zooanthroponosis, infection that is transmitted from man to animals, by means of domestic vectors, which is the rarest situation in areas endemic for Chagas disease. The characteristics of Chagas disease as an enzooty of wild animals and as an anthropozoonosis are seen most frequently in the Brazilian Amazon and in the Pan-Amazon region as a whole, where there are 33 species of six genera of wild animals: Marsupialia, Chiroptera, Rodentia, Edentata (Xenarthra), Carnivora and Primata and 27 species of triatomines, most of which infected with T. cruzi. These conditions place the resident populations of this area or its visitors - tourists, hunters, fishermen and especially the people whose livelihood involves plant extraction - at risk of being affected by Chagas disease. On the other hand, there has been an exponential increase in the acute cases of Chagas disease in that region through oral transmission of $\mathrm{T}$. cruzi, causing outbreaks of the disease. In four seroepidemiological surveys that were carried out in areas of the microregion of the Negro River, state of Amazonas, in 1991, 1993, 1997 and 2010, we found large numbers of people who were serologically positive for T. cruzi infection. The majority of them and/or their relatives worked in piassava extraction and had come into contact with and were stung by wild triatomines in that area. Finally, a characteristic that is greatly in evidence currently is the migration of people with Chagas disease from endemic areas of Latin America to non-endemic countries. This has created a new dilemma for these countries: the risk of transmission through blood transfusion and the onus of controlling donors and treating migrants with the disease. As an enzooty of wild animals and vectors, and as an anthropozoonosis, Chagas disease cannot be eradicated, but it must be controlled by transmission elimination to man.
\end{abstract}

Key words: Chagas disease - Trypanosoma cruzi - control eradication - surveillance

Three cycles of Chagas disease may interchange: the wild cycle, the peridomestic cycle and the domestic cycle of the infection. Triatomines and some wild animals (especially marsupials) visit human peridomestic areas in search of food: the blood of peridomestic animals for the triatomines and other types of food for the wild animals, in the goat, sheep or cattle pens, henhouses and pigsties. Triatomines have been feeding in these places especially as a consequence of deforestation and separation from their original wild food sources, thus gradually adapting to peridomestic areas. In contrast, in a two-way movement, the animals of peridomestic areas visit the wild ecotope for pasture and, in the case of dogs and cats, to hunt, where they become infected by eating the meat of wild animals. Subsequently, the peridomestic vectors may gradually invade the human domicile and adapt to the domestic cycle, feeding from human blood. In certain situations, wild triatomines may be directly attracted towards the human domicile by the light and

\footnotetext{
doi: 10.1590/0074-0276130565

Financial support: CNPq (471716/2009-0)

+ Corresponding author: coura@ioc.fiocruz.br

Received 2 December 2013

Accepted 9 December 2013
}

may even seek to feed from human blood when their original food sources in the wild environment are scarce. In a similar manner, marsupials and bats may invade the human domicile directly in search of food. On the other hand, humans and their anthropic actions, such as deforestation, extracting plants for food, for building houses, for industrial use, in the case of piassava fibres or for hunting, among other activities, invade the wild ecotope, where they can become infected with Trypanosoma cruzi and even carry infected wild triatomines to their homes, together with the wood, fibres and palm leaves that are frequently used as roofing material for houses in rural areas. Thus, a "two-way" exchange occurs with the three cycles of Chagas disease, with the central axis comprising the reservoirs, T. cruzi, the vectors and human beings, as summarised in Fig. 1 (Coura \& Dias 2009).

The main objective of this review was to draw attention towards the urgent and unpostponable need to encourage countries to undertake surveillance and control and, if possible, to eliminate or eradicate Chagas disease from endemic countries and avoid the migration of people who are already infected by T. cruzi to non-endemic countries. These countries then need to be concerned about locating migrants who are already infected, treating them and following up their condition, so as to avoid transmission of the infection by such individuals as blood donors or in the form of vertical transmission from infected mothers to their offspring. 
Surveillance and control of Chagas disease in Latin America - The epidemiological surveillance of Chagas disease must consist of continually ongoing studies on the following: occurrences of the disease, the environment, the transmission mechanisms, the risks of adaptation of the triatomines to domestic and peridomestic areas, human infection by $T$. cruzi and patients who have already been infected and control through various mechanisms of vector transmission, via blood transfusion, oral transmission and other less frequent mechanisms. Four surveillance and control initiatives for Chagas disease have been created so far by the Ministries of Health of South and Central American countries, with intermediation from Pan-American Health Organization (PAHO)/ World Health Organization (WHO): in 1991 the Southern Cone Initiative (INCOSUR) was created, comprising Argentina, Brazil, Chile, Paraguay and Uruguay; in 1997, the Andean Country Initiative (IPA) was created: Bolivia, Colombia, Ecuador, Peru and Venezuela; in 1998, an initiative for the countries of Central America and Mexico was created: Belize, Costa Rica, El Salvador, Guatemala, Honduras, Nicaragua and Panama; in 2004, the Amazon Country Initiative (AMCHA) was created: Bolivia, Brazil, Colombia, Ecuador, Guyana, French Guyana, Peru, Suriname and Venezuela. Some of these, like Brazil, are also part of the INCOSUR and, others, the IPA. Fig. 2 shows the limits of the four initiatives (Guhl 2007).

Chagas disease needs to be controlled through a set of measures to reduce or eliminate transmission of the disease by its many mechanisms, particularly vector transmission, transmission through blood transfusion and oral transmission. The basic control measures comprise: education for the population to avoid domestication of triatomines, improvement of housing and separation from henhouses, pigsties and animal pens, spraying of homes and annex buildings infested by triatomines, using residual insecticides (e.g., pyrethroids), control over blood donors using at least two serological reactions with

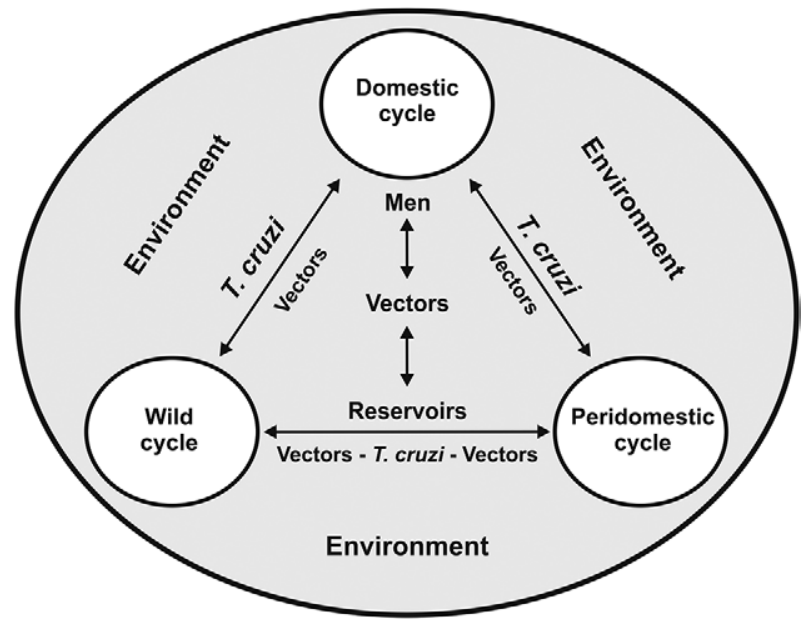

Fig. 1: interchanges between wild, peridomestic and domestic cycles of Trypanosoma cruzi [adapted from Coura and Dias (2009)] different principals (e.g., ELISA and immunofluorescence), cooking foods thoroughly or applying hygiene measures to foods that should be eaten raw, such as salads and fruits, which should be well washed, with special care in preparing and consuming fruit juices such as acai, bacaba, guava and sugar cane, among others, which have been held responsible for outbreaks of Chagas disease through oral transmission (Coura 2006, Pinto et al. 2008, Coura \& Dias 2009, Dias 2009, Valente et al. 2009, Coura \& Junqueira 2012, Noya et al. 2012, Shikanai-Yasuda \& Carvalho 2012, Souza-Lima et al. 2013).

Situation and control of Chagas infection caused by domestic Triatoma infestans and Rhodnius prolixus - The Southern Cone Chagas disease control initiative, which began in 1991, includes Brazil, Argentina, Chile, Paraguay and Uruguay. The greatest successes have been obtained chronologically by Uruguay, which received certification of complete elimination of T. infestans by the PAHO/WHO in 1997. Chile was certified in 1999 and Brazil in 2006 (Dias 2009, Abad-Franch et al. 2013). The blood banks of Brazil and Uruguay are now totally controlled for this disease and Chile is completing this control. Argentina faced a series of difficulties relating to its public health services, but has still been successful in some place, including most recently in Santiago del Estero, which has ceased to have acute cases of the disease. Paraguay had great success in eliminating of $T$. infestans from its eastern oriental region, including in the Gran Chaco. In Peru and Bolivia, despite some initiatives, $T$. infestans has not been brought under control because it is a native species. Regarding the domestic $R$. prolixus introduced into Central America and Mexico, there is strong evidence that the vector transmission of $T$. cruzi was halted in Guatemala in 2008, in southern Mexico in

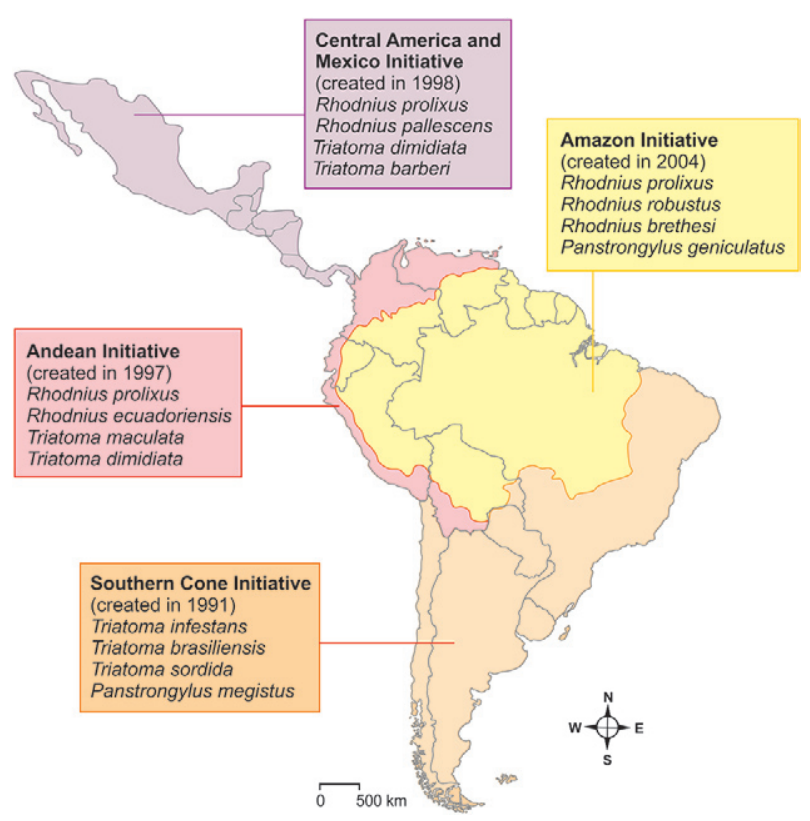

Fig. 2: continental initiatives for controlling the main vectors of Chagas disease [adapted from Guhl (2007)] 
2009, in Honduras, El Salvador and Nicaragua in 2010 and in Costa Rica in 2011 (Hashimoto \& Schofield 2012, Abad-Franch et al. 2013). However, rigorous surveillance is extremely important in these countries to detect and eliminate focuses of either residual infection or infection resulting from reintroduction of $R$. prolixus into these countries, according to Abad-Franch et al. (2013). In Colombia, where the domestic $R$. prolixus is mostly native, there is a broad surveillance program, especially in rural and periurban areas. This situation is repeated and, up to a certain point, is more severe in the other three countries of the Andean Initiative (Ecuador, Peru and Venezuela), due to fewer surveillance and control activities. We strongly recommend that readers should review the lucid opinion of the abovementioned authors and critically and lucidly analyse the concept of certification for interruption of vector transmission of Chagas infection.

Surveillance and control initiatives for Chagas disease in the Americas and in non-endemic countries - The surveillance and control initiatives for Chagas disease in the Americas and non-endemic countries were examined by a group of experts at the 25th Applied Research Meeting on Chagas Disease, which was held in Uberaba, state of Minas Gerais, Brazil, in October 2009. It reached the following conclusions (Coura et al. 2009).

Multinational initiatives for controlling Chagas disease are present in the countries of the INCOSUR, the Andean countries, Central America and Mexico, the Amazon Region and the non-endemic countries. These international efforts have enabled huge advances in prevention of vector transmission of Chagas disease and its transmission through blood transfusion. However, there are still great challenges ahead, including: (i) incentives for establishment of political priority for controlling Chagas disease, (ii) reinforcement of the international coordination and evaluation of national programs through the initiatives and (iii) definition and effective implementation of the quality standards for all the preventive actions. Priority must be given towards vector and blood bank control and towards patient healthcare, including specific treatment of acute cases and of patients in the chronic phase, particularly in the indeterminate and lowmorbidity forms (Coura \& Borges Pereira 2011).

INCOSUR - The Ministers of Health of Argentina, Brazil, Chile, Paraguay and Uruguay met in Brasília in July 1991 to discuss the strategies for controlling Chagas disease in their respective countries. In this regard, the ministers decided to create an Intergovernmental Commission for the Control of Chagas Disease, with the PAHO as secretary of the subregional program. This effort sought to stimulate the national plans of each country and cooperative relationships among the countries of the region.

The objectives of the subregional INCOSUR were: (i) to eliminate $T$. infestans from domestic and peridomestic areas in the endemic regions, (ii) to reduce or eliminate infestation due to triatomine species other than $T$. infestans in domestic and peridomestic areas in the same regions and (iii) to reduce and eliminate the transmission of T. cruzi through blood transfusion through serological control over donors in blood banks.
The vector elimination program was planned to take 10 years, including spraying with residual insecticide in domestic and peridomestic areas every three months during the first year (attack phase), complemented by epidemiological surveillance and serological monitoring of infection levels in the resident population in the region. This surveillance activity was planned to be continuous and therefore counted on participation by the community. Insecticide spraying in homes would have to be repeated in situations of reinfestation of triatomines (Coura \& Dias 2009, Dias 2009, Amelotti et al. 2012).

The first meeting of the Intergovernmental Commission took place in Buenos Aires, Argentina, in 1992, and activities were planned for the period of 1992-1995. In most countries, the policy for halting Chagas disease transmission through triatomines and blood transfusion was funded by the countries themselves. The spraying plans for homes were established by the respective countries (Argentina, Brazil, Chile, Paraguay and Uruguay) and large numbers of homes were sprayed. Successive meetings of the Intergovernmental Commission were held in Bolivia, Uruguay, Paraguay, Brazil and Chile, respectively in 1993, 1994, 1995, 1996, 1997. The objective of these meetings was to assess the results from the various countries of the Southern Cone with regard to controlling the transmission of T. cruzi infection through vectors and blood transfusion. Finally, transmission through T. infestans was halted in Uruguay in 1997, in Chile in 1999 and in Brazil in 2006, which were certified by PAHO as free from this vector and, therefore, from Chagas infection transmission by this species in these three countries. However, we need to remain vigilant in these countries to avoid reintroduction of $T$. infestans, which still exists in Argentina, Bolivia, Paraguay and Peru and of other species that have not been eliminated (Abad-Franch et al. 2013).

$I P A$ - The surveillance and control initiative towards Chagas disease in the IPA was officially created in 1997, including Colombia, Ecuador, Peru and Venezuela. The high ecological diversity of the Andean subregion is reflected in the diversity of species of vectors, which causes great difficulty in controlling them. R. prolixus is the main domestic vector in Venezuela, which maintains vector populations in some states of the region and Triatoma maculata is a secondary domestic species in some states of that country. In Colombia, transmission by $R$. prolixus, the main domestic vector species, was halted. Other vectors, such as Triatoma dimidiata and Rhodnius pallecens are candidate vectors in some areas of that country. In Ecuador, T. dimidiata, which was artificially introduced, is a candidate for elimination in the coastal region. In addition, populations of domestic Rhodnius equacuadoriensis on the western coast and in the southern Andean valleys are another concern. This species is also present in homes in northern Peru, but these are usually distinct populations and may be independent targets in Ecuador, except in border areas. Panstrongylus herreri is another important vector, particularly in the valley of the Marañon River. In southern Peru, the elimination of $T$. infestans is a main priority. 
Control over blood donors, by means of serological screenings to detect infection by $T$. cruzi is currently mandatory in all Andean countries (Guhl \& Schofield 2004, Coura et al. 2009).

Central America and Mexico Initiative - The initiative for Central America was formally recognised in September 1997. As a consequence of this resolution, a meeting on the vectors of Chagas disease was held in Tegucigalpa, Honduras, in October of the same year. The main recommendations from the multinational initiative for halting Chagas disease transmission in Central America were: (i) to halt Chagas disease transmission by $R$. prolixus in the region, (ii) to decrease home infestation of $T$. dimidiata and (iii) to halt $T$. cruzi transmission through blood transfusion.

In Guatemala, $100 \%$ of the homes with $R$. prolixus were sprayed with insecticides with the aid of the Japan International Cooperation Agency, resulting in halting of Chagas disease transmission by this vector in 2008. In El Salvador, improvement of housing in rural areas (plaster on the walls and renovation of the roofing) together with malaria control through spraying insecticides in homes resulted in elimination of $R$. prolixus, which was no longer found in entomological investigations. On the other hand, $90 \%$ of the territory of Honduras was considered free from triatomines. However, infestation of homes by $R$. prolixus seems to exist only in some neglected areas, occasionally with wild $T$. dimidiata (Coura et al. 2009).

In conclusion, the current situation in Central America and Mexico is that there is strong evidence that vector transmission of $T$. cruzi by $R$. prolixus was halted in Guatemala in 2008, in southern Mexico in 2009, in Honduras, El Salvador and Nicaragua in 2010 and in Costa Rica in 2011 (Hashimoto \& Schofield 2012, Hashimoto et al. 2012, Abad-Franch et al. 2013). Evaluations that are currently in progress suggest that $T$. dimidiata, a native species of the region, invades and reinfests homes, which requires implementation of continuous entomological surveillance. In Panamá, the invasion of homes by Rhodnius pallesceus coming from peridomestic palm trees can maintain transmission in the absence of domestic vectors, i.e. a similar situation to what occurs in the Amazon Region, with other wild vectors.

AMCHA - Chagas disease in the Amazon Region can be characterised by the following patterns: (i) an enzooty exchanged by wild vectors, which may be transmitted to humans when either they invade the wild ecotope or when the vectors and wild animals, especially marsupials, invade human homes, a situation that characterises an anthropozoonosis (Coura et al. 1993, 2002, Coura \& Junqueira 2012), (ii) an endemic disease through oral transmission of $T$. cruzi by means of consumption of juices and other uncooked foods and foods contaminated by the faeces and urine of wild triatomines or odoriferous secretion of marsupials, thereby causing acute outbreaks of the disease (Valente et al. 1999, 2009, Pinto et al. 2003, 2008, Coura 2006, Coura \& Junqueira 2012, Souza-Lima et al. 2013) and (iii) a professional disease among people who work in plant extraction, especially piassava gatherers, who suffer attacks by wild triatomines (Rhodnius brethesi) (Brum-Soares et al. 2010, Coura \& Junqueira 2012, Coura et al. 2013). The AMCHA began officially in 2004, at a meeting held in Manaus, Brazil, after a preparatory meeting held in Palmari, on the border of Brazil and Colombia in 2002, promoted by European Community Latin America Triatominae (Guhl \& Schofield 2004). Representatives from the nine Amazon countries took part in the meeting to create AMCHA: Bolivia, Brazil, Colombia, Ecuador, Guyana, French Guyana, Peru, Suriname and Venezuela, which established the following objectives: (i) training of primary school teachers, so that they would be able to multiply the knowledge on Chagas disease and its surveillance, (ii) active participation by schoolchildren in entomological surveillance (notifying the presence of triatomines in peridomestic and domestic areas), (iii) training of microscopists in the malaria services to identify trypanosomes in thick blood smears in plasmodium investigations and to identify triatomines that are sent to them, (iv) carrying out seroepidemiological investigations to detect people infected with $T$. cruzi and (v) training of healthcare professionals in the Amazon Region to diagnose and treat patients in the acute phase of Chagas disease and send them to regional reference centres for management of chronic cases of the disease, identified through serology.

Eradication, elimination and control of Chagas disease - Eradication of a disease is the complete and permanent suppression or extinguishment of this disease. According to the WHO, the term eradication should only be used when there is permanent reduction to zero of worldwide incidence of an infection caused by a specific infectious agent as the result of deliberate actions, such that there is no more need for continuous intervention measures. For example, the eradication of smallpox was completed in 1977 and was confirmed by WHO on May 8, 1980. WHO recommends reserving the word elimination for reduction to zero of the incidence of a certain disease in a defined geographical area, as a result of deliberate actions, but requiring continued intervention measures for surveillance and control. Thus, elimination differs from eradication since it requires continued control or epidemiological surveillance actions, while eradication does not demand these actions. For example, the PAHO/WHO certified the elimination of T. infestans in Uruguay in 1997, in Chile in 1999 and in Brazil in 2006 (Fig. 3). This means that these countries must continue to conduct epidemiological surveillance actions and, if necessary, control actions to eliminate possible residual foci of triatomines or to avoid their reintroduction in these countries.

Control consists of reduction or halting of transmission of a disease in a certain region or country. For example, transmission of T. cruzi infection in Brazil by $T$. infestans and by blood transfusion is under control in Brazil, but there are still residual foci of T. infestans in the states of Rio Grande do Sul and Bahia. Therefore, there is still a risk of reintroduction of this triatomine into Brazil and control actions towards the insect need to continue in the residual foci and epidemiological surveillance actions need to be carried out throughout the country in relation to vectors and blood banks. 
Is it possible to eradicate Chagas disease? - As seen in the introduction of this review, Chagas disease is characterised as an enzooty of wild animals and vectors found universally from southern USA to southern Argentina and Chile; as an anthropozoonosis, when man invades the wild ecotope or when wild vectors and animals invade human domestic and peridomestic areas; as a zoonosis-amphixenosis and possibly as a zooanthroponosis, meaning infection of animals by $T$. cruzi that infects man. On the other hand, we cannot eliminate more than 100 species and their genera of reservoir animals for T. cruzi or 150 species of triatomines (which are mostly wild) or even some of the 13 domestic species, especially the native ones, which may be part of the wild and domestic cycles, as is the case of T. infestans in Bolivia and Peru, Panstrongylus megistus, Triatoma sordida, Triatoma brasiliensis and Triatoma pseudomaculata in Brazil and T. dimidiata in Central America and Mexico. Oral transmission of $T$. cruzi is certainly a very important issue in maintaining endemic Chagas disease.

Another great problem, of major importance, is Chagas disease in non-endemic countries, which results from migration of patients with the disease from endemic countries to non-endemic countries, as is the case of the USA, Canada, European and Asian countries, Australia and others (Coura \& Viñas 2010). The great risk in these cases is the lack of diagnosis and control over blood donors, which is generally not done in non-endemic countries, in addition to the onus relating to control of blood banks and medical care for infected migrants with Chagas disease.

Finally, our answer in the light of these facts is that it is not possible to eradicate Chagas disease, but it is possible to control it, through elimination of domestic

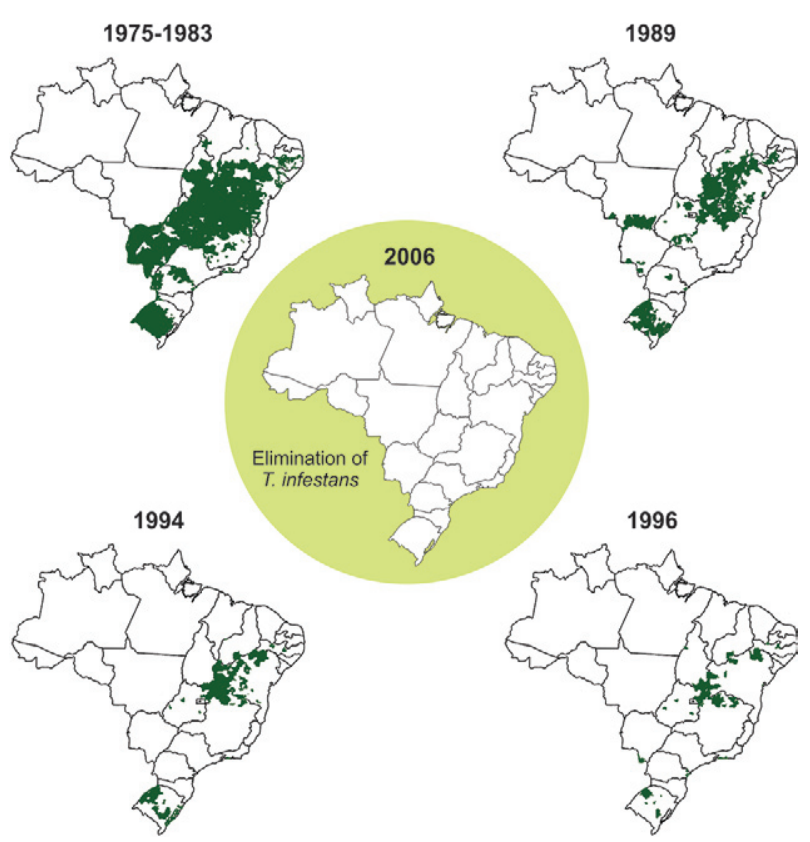

Fig. 3: elimination of Triatoma infestans from Brazil [adapted from Coura and Dias (2009)]. vectors, control over blood donors all over the world, treatment for patients in the acute and chronic phases of the disease, education for the population to avoid oral transmission of the infection and maintenance of "eternal vigilance".

\section{ACKNOWLEDGEMENTS}

To Heloísa Diniz, for producing the figures of this paper.

\section{REFERENCES}

Abad-Franch F, Diotaiuti L, Gurgel-Gonçalves R, Gürtler RE 2013. Certifying the interruption of Chagas disease transmission by native vectors: cui bono? Mem Inst Oswaldo Cruz 108: 251-254.

Abad-Franch F, Monteiro FA 2007. Biogeography and evolution of Amazonian triatomiones (Hemiptera: Reduviidae): implications for Chagas disease surveillance in humid forest ecoregions. Mem Inst Oswaldo Cruz 102 (Suppl. I): 57-69.

Amelotti I, Catalá SS, Gorla DE 2012. The residual efficacy of a cypermethrin pour-on formulation applied on goats on the mortality and blood intake of Triatoma infestans. Mem Inst Oswaldo Cruz 107: 1011-1015.

Brum-Soares LM, Xavier SS, Sousa AS, Pereira JB, Ferreira JMBB, Costa IR, Junqueira ACV, Coura JR 2010. Morbidade da doença de Chagas em pacientes autóctones da microrregião do Rio Negro, estado do Amazonas. Rev Soc Bras Med Trop 43: 170-177.

Coura JR 2006. Transmisão da infeccção chagásica por via oral na história natural da doença de Chagas. Rev Soc Bras Med Trop 39 (Suppl. IV): 113-117.

Coura JR, Abad-Franch F, Aguilera X, Dias JCP, Junqueira ACV, Lima JF, Moreira JCC, Schall V, Schmanis G 2009. The iniciative for the control of Chagas disease in the Americas and in non-endemic countries. Rev Soc Brasi Med Trop 42 (Suppl. II): 106-110.

Coura JR, Borges-Pereira J 2011. Chronic phase of Chagas disease: why should it be treated? A comprehensive review. Mem Inst Oswaldo Cruz 106: 641-645.

Coura JR, Dias JCP 2009. Epidemiology, control and surveillance of Chagas disease - 100 years after its discovery. Mem Inst Oswaldo Cruz 104 (Suppl. I): 31-40.

Coura JR, Junqueira ACV 2012. Risks of endemicity, morbidity and perspectives of regarding the control of Chagas disease in the Amazon Region. Mem Inst Oswaldo Cruz 107: 145-154.

Coura JR, Junqueira ACV, Boia MN, Fernandes O 1999. Chagas disease: from bush to huts and houses. Is it the case of the Brazilian Amazon? Mem Inst Oswaldo Cruz 94 (Suppl. I): 379-384.

Coura JR, Junqueira ACV, Fernandes O, Valente SAS, Miles MA 2002. Emerging Chagas disease in Amazonian Brazil. Trends Parasitol 18: 171-176.

Coura JR, Marquez PHP, Guerra JAO, Zauza PL, Miguel JC, Pereira JB 2013. A new survey of the serology of human Trypanosoma cruzi infection in the Rio Negro microregion, Brazilian Amazon: a critical analysis. Mem Inst Oswaldo Cruz 108: 909-913.

Coura JR, Naranjo MA, Willcox HPF 1993. Doença de Chagas na Amazônia brasileira. Rev Soc Bras Med Trop 26 (Suppl. 2): 15-17.

Coura JR, Viñas PA 2010. Chagas disease: a new worldwide challenge. Nature 465: S6-S7.

Dias JCP 2009. Elimination of Chagas disease transmission: perspectives. Mem Inst Oswaldo Cruz 104 (Suppl. I): 41-45.

Guhl F 2007. Chagas disease in Andean countries. Mem Inst Oswaldo Cruz 102 (Suppl. I): 29-37. 
Guhl F, Schofield CJ 2004. Proceedings of the ECLAT-AMCHA international workshop on Chagas Disease surveillance in the Amazon Region, CIMPAT, Universidad de los Andes, Bogotá, 160 pp.

Hashimoto K, Álvarez H, Nakagawa J, Juarez J, Monroy C, CordónRosales C, Gil E 2012. Vector control intervention towards interruption of transmission of Chagas disease by Rhodnius prolixus, main vector in Guatemala. Mem Inst Oswaldo Cruz 107: 877-887.

Hashimoto K, Schofield CJ 2012. Elimination of Rhodnius prolixus in Central America. Parasit Vectors 5: 45.

Noya BA, Díaz-Bello Z, Colmenares C, Zavala-Jaspe R, Abate T, Contreras R, Losada S, Artigas D, Mauriello L, Ruiz-Guevara R, Noya O 2012. The performance of laboratory tests in the management of a large outbreak of orally transmitted Chagas disease. Mem Inst Oswaldo Cruz 107: 893-898.

Pinto AY, Valente SAS, Valente VC 2004. Emerging acute Chagas disease in Amazonian Brazil: cases reports with serious cardiac involvement. Braz J Infect Dis 8: 454-460.

Pinto AYN, Valente SAS, Lopes R, Silva O, Castro T, Valente VC 2003. Ocorrência de tripanosomíase aguda familiar no municí- pio Igarapé-Mirim, Pará: gravidade de apresentação clínica em idosos. Rev Soc Bras Med Trop 36 (Suppl. 1): 381.

Pinto AYN, Valente SAS, Valente VC, Ferreira-Junior AG, Coura JR 2008. Fase aguda da doença de Chagas na Amazônia brasileira. Estudo de 233 casos do Pará, Amapá e Maranhão observados entre 1988 e 2005. Rev Soc Bras Med Trop 41: 602-614.

Shikanai-Yasuda MA, Carvalho NB 2012. Oral transmission of Chagas disease. Clin Infect Dis 54: 845-852.

Souza-Lima RC, Barbosa MGV, Coura JR, Arcanjo ARL, Nascimento AS, Ferreira JMBB, Magalhães LK, Albuquerque BV, Araujo GAN, Guerra JAO 2013. Outbreak of acute Chagas disease in the Rio Negro Region, Brazilian Amazon. Rev Soc Bras Med Trop 46: $510-514$.

Valente SAS, Valente CV, Pinto AYN, César MJR, dos Santos MP, Miranda COS, Cuervo P, Fernandes O 2009. Analysis of an acute Chagas disease outbreak in the Brazilian Amazon: human cases, triatomines, reservoir mammals and parasites. Trans $R$ Soc Trop Med Hyg 103: 291-297.

Valente SAS, Valente VC, Fraiha Neto H 1999. Considerations on the epidemiology and transmission of Chagas disease in the Brazilian Amazon. Mem Inst Oswaldo Cruz 94 (Suppl. I): 395-398. 